\title{
Introduction from the Special Issue Editors
}

\section{Quality Enhancement: Teaching Preparation for Graduate Teaching Assistants}

Lianne Fisher, Lorraine Godden, Shaya Golparian, Aisha Haque, Betsy Keating, Cynthia Korpan, Suzanne Le-May Sheffield, Annie Riel, Christina Skorobohacz, Roselynn Verwoord, and Kim West ${ }^{1}$

Graduate teaching assistants (GTAs) occupy a unique position in teaching and learning in higher education. Typically, individuals arrive at graduate school already socialized into disciplinary ways of knowing. GTA pedagogical professional development offers opportunities for GTAs to engage with current "best practices" and different pedagogical ways of knowing, and to initiate new and innovative practices. Research has demonstrated that as content knowledge and expertise develop, experienced instructors do not always recognize the ways that their expertise (e.g., how they organize materials or knowledge) can interfere with student learning (Ambrose, Bridges, DiPietro, Lovett, \& Norman, 2010). GTAs are therefore well positioned to scaffold learning for content novices such as undergraduate students. The teaching preparation and pedagogical development of GTAs is not just a resource to support learning; in fact, the teaching and instructional skills that GTAs acquire can be transferred to professional domains outside academia (Osborne, Carpenter, Burnett, Rolheiser, \& Korpan, 2014; Rose, 2012). GTA professional development has never been just training to fulfill a particular niche or to achieve a singular goal such as teaching; however, the current post-secondary climate of accountability and quality enhancement does bring the goals and purposes of GTA professional development into view.

In current practice, quality assurance and quality enhancement are being differentiated in terms of focus. Quality assurance, like summative evaluation or quantitative methodology, has an outcome focus. On the other hand, quality enhancement, like formative evaluation or qualitative methodology, has a process focus (Kinzie, 2013). An argument 
can be made for suggesting that neither approach is better or worse than the other; instead, it is important to reflect on the alignment between the approach and goals, which includes the processes. An approach that focuses on both outcome and process, the whole of a project, "promotes deeper understanding of the nature of complex change" (Fleming, 2013, p. 22). To promote quality enhancement more fully, perhaps it is time to give significant consideration to how we frame research, in terms of aligning the goal (outcome/ process) with the methodology, rather than focusing on the limitations of each piece of research. Similar to research and teaching, quality enhancement is not like ticking off boxes on a checklist; rather, it is a process of ethical judgments, questions, and meaning (Moss \& Petrie, 2006). Readers will see throughout this special issue a variety of methods that help to address "enhancing the quality of graduate student teaching."

Through these papers, readers will learn about the use of reflective practice, feedback, mentorship, and engagement in teaching practice-each of which are qualities recognized as fostering learning. It is evident from the research contained in this volume that the aforementioned components are indicators of the processes that enhance GTA teaching and professional development.

The value of the experience of teaching is highlighted throughout the manuscripts, whether this experience is gleaned in an online environment (Sheffield, McSweeney, \& Panych), as part of a role-play activity (Lekhi \& Nussbaum), via micro-teaching (Meadows, Olsen, Dimitrov, \& Dawson; Troop, Wallar, \& Aspenlieder), or through independent course instruction (Starr \& DeMartini). The importance and central role of feedback and reflective practice to effective teaching is evident in the works across this special issue, particularly feedback, and reflections that feed back into the teaching and learning processes (Parker, Ashe, Boersma, Hicks, \& Bennett).

\section{The Papers}

The first paper in this special issue, "Exploring Future Teachers' Awareness, Competence, Confidence, and Attitudes Towards Teaching Online: Incorporating the Blended/ Online Experience into a Teaching and Learning in Higher Education Course for Graduate Students" (Sheffield, McSweeney, \& Panych), addresses an area of graduate student development that has previously been unexplored-how to prepare graduate students to teach online. Their study shows how training and support alleviate fears, increase competence, and promote a positive attitude regarding working on an online course. Despite participants still favouring face-to-face instruction, it is suggested that further support with how to teach online would eventually sway individuals by helping them understand how to get the most from teaching online. The authors emphasize that educational developers have the necessary task of including instruction about the teaching of blended and online courses in their professional development courses for graduate students.

In the second paper, "Developing Graduate Students' Self-Efficacy with Learner-Centred Lecturing," the authors (Troop, Wallar, \& Aspenlieder) examine the relationship between practice lecturing and graduate student self-efficacy, through a mixed-method case study conducted at the University of Guelph. The study reveals that self-efficacy increased for all participants due to practice teaching and critical reflection components. In addition, although typical workshop experiences were beneficial, when practice teaching was added to workshops, there were significant learning gains associated with micro-teaching cycles 
that involved self, peer, and instructor feedback. Troop et al. conclude that, whilst a typical workshop provides sound introductions to teaching most topics or issues, there is a need for mobilizing theory into practice to leverage learner strengths and build teaching capacity.

The third paper in this issue, "Evaluating the Differential Impact of Teaching Assistant Training Programs on International Graduate Student Teaching" (Meadows, Olsen, Dimitrov, \& Dawson), compares the relative impact of general and specialized teaching assistant training programs on international GTAs' self-efficacy and effectiveness. Using a mixed-method design combining measures of self-efficacy with teaching observations and focus groups, the authors determine that programs with a substantial intercultural component not only result in greater gains in international GTAs' effectiveness and their adoption of student-centred teaching approaches than programs without such a component, but also enhance their ability to become reflective practitioners and adapt their teaching approaches to new situations. This research contributes to the discussion of international graduate student development in the Canadian context and has important implications for the future design of international teaching assistant training programs.

In the fourth paper, "Strategic Use of Role-Playing in a Training Workshop for Chemistry Laboratory Teaching Assistants," Lekhi and Nussbaum report on a training program that employed strategic role-playing activities to help chemistry laboratory teaching assistants bridge the gap between learning about effective teaching strategies and being able to use them with confidence. Asserting that few studies have discussed specific techniques aimed to increase teaching assistants' skills in a laboratory setting, the authors seek to address this deficit with their study of attendees in a training workshop held in the Department of Chemistry at the University of British Columbia, on four different occasions, over a four-year period (2010 to 2014). Lekhi and Nussbaum's findings suggest that roleplaying activities could offer inexperienced teaching assistants increased opportunities to situate learning so as to teach within a safe community of practice (Lave \& Wenger, 1991).

The fifth paper, "Addressing the Needs of Doctoral Students as Academic Practitioners: A Collaborative Inquiry on Teaching in Higher Education" (Starr \& DeMartini), begins by positioning a pilot project between a graduate student and faculty member within the complex and evolving landscape of higher education-where neoliberal ideals, increased contract work and competition, and decreased funding and job security dominate. The authors explain that this context has significant implications for graduate student employment and undergraduate education. As evidenced in DeMartini's narratives, new doctoral student instructors in particular may find themselves struggling to manage conflicting emotions, achieve ambitious teaching goals, fulfill extensive duties, and explore challenging subject matter with students. In an effort to recognize, question, and confront the intricacies of teaching, the two individuals provide an account of their mutually beneficial collegial relationship built upon candid reflexion in a creative, safe, and supportive space, via the use of dialoguing, private blogging, teaching observations, and debriefs. Through collaborative inquiry and self-study, and with critical reflexivity and relational dialogic pedagogy at the centre, they attend to, and learn from, some of their instructional mistakes, recognizing that these "teachable moments" hold the potential to transform themselves, their peers, their students, their courses, and their scholarship. Ultimately, through the pilot project, both authors gain multifaceted knowledge of themselves and their teaching, which they use to strengthen their practice. 
The sixth paper, "Good Teaching Starts Here: Applied Learning at the Graduate Teaching Assistant Institute" (Parker, Ashe, Boersma, Hicks, \& Bennett), focuses on supporting graduate teaching assistants in learning how to help students learn, rather than merely in learning what to teach. Recognition that learning and teaching is a complex area necessitates ensuring that GTAs are sufficiently prepared to support students in their learning. The authors measured GTAs' confidence through pre- and post-program questionnaires, and they discuss the ways one institution instructed and supported GTAs to understand and use applied learning in their classrooms.

The articles of this special issue point clearly to quality in fostering the craft of teaching. TA training, and the mentoring of graduate students as post-secondary educators, is rooted in the experience of teaching and in how people make meaning of what they do. We hope this special issue provides readers with both the questions and the contexts in which to (a) consider their work and (b) seek out knowledge to inform their practice. In these pages, we hope that readers will find ideas, practices, indicators, and processes that generate reflection and options for modifying, developing, and valuing GTA programming and professional development.

As you engage with the work in this special issue, we hope you will consider the context in which the articles, the various methodologies, and this body of knowledge are taken up and applied, bringing your own critical reflective practice to the enhancement of quality. Let us not position quality as an outcome that sits outside the daily messy work of teaching and learning. To quote from one pair of authors in this special issue, "Learning how to teach in post-secondary settings should also be at the heart of any higher education institution." Let us engage in the "mass of complex tangles" that comprise teaching and learning (Starr \& DeMartini, 2015, this volume).

The authors of these articles ask each one of us to think of the specific context of higher education and the unique and important contribution graduate students, often in the role of teaching assistants, provide to undergraduate education and instruction. As expected, you will hear a variety of voices within these pages, reflecting the many ways in which quality can be conceived; you will also read a commitment to valuing and sharing the voices of the GTAs. In this compilation are papers with well-accepted, evidenced-based approaches, and investigations from dialogic and reflective approaches, hallmarks of the methods that demonstrate impact in teaching and learning (Brookfield, 1995). Dialogic, reflective, and mixed methodologies orient individuals to multiple forms of evidence and ask them to engage with accountability and evaluation in many forms. To act as informed citizens for quality improvement and accountability, and for quality assurance and enhancement, we must be able to think about and wrestle with the evidence given to us, to "weigh evidence and think evaluatively" (Quinn Patton, 2002, p. 127).

\section{Conclusion}

Quality assurance in higher education can only be achieved if individuals first focus on quality enhancement. As Gordon and Owen (n.d.) noted in their overview Cultures of Quality Enhancement, "it is no longer helpful to think about quality merely in terms of maintaining standards. Instead, higher education institutions, like many other organisations, are being encouraged to take a developmental approach to quality" (p. 1). Teaching assistants are central to the teaching and learning endeavour at many institutions of 
higher learning. The focus for course instructors and educational developers should be on the development of key teaching competencies for GTAs to ensure effective teaching, positive learning experiences, and successful learning outcomes.

An emphasis on the developmental process is at the heart of this special issue. The articles speak to the myriad opportunities that exist to support and develop teaching assistants as teachers, now and in the future. The goal should be not only to change what graduate student teachers do in the classroom, but also to impact what they intrinsically believe about teaching and learning. In this way, teachers will be motivated by their own sense of conviction gained through their professional development experiences and reflections. We must ensure not only that teaching standards are being met, but that teaching assistants in higher education will engage in an ongoing process of professional development and reflection, in turn enhancing students' learning experiences.

\section{Note}

1. The special issue editors make up the Executive Committee of Teaching Assistant and Graduate Student Advancement (TAGSA), a special interest group of the Society for Teaching and Learning in Higher Education (STLHE). The editors and their corresponding biographical notes are listed in alphabetical order by surname.

\section{References}

Ambrose, S. A., Bridges, M. W., DiPietro, M., Lovett, M. C., \& Norman, N. J. (2010). How learning works: Seven research-based principles for smart teaching. San Francisco, CA: Jossey-Bass.

Brookfield, S. (1995). Becoming a critically reflective teacher. San Francisco, CA: Wiley and Sons.

Fleming, A. (2013). Developmental evaluation and the "double loop": Adding value to the evaluation of complex change. In R. Macdonald (Ed.), Staff and Educational Development Association (SEDA): Special 33. Supporting educational change (pp. 2125). London, UK: SEDA.

Gordon, G., \& Owen, C. (n.d.). Cultures of quality enhancement: A short overview of the literature for higher education policy makers and practitioners. Retrieved from http://www.enhancementthemes.ac.uk/docs/report/cultures-of-quality-enhancementoverview-for-higher-education-policy-makers-and-practitioners.pdf?sfvrsn $=30$

Kinzie, J. (2013). Assessing and improving student learning and educational quality. In K. Norrie \& M. C. Lennon (Eds.), Measuring the value of a postsecondary education (Queen's Policy Studies Series, No. 162, pp. 105-121). Montreal, QC, and Kingston, ON: McGill-Queen's University Press.

Lave, J., \& Wenger, E. (1991). Situated learning: Legitimate peripheral participation. New York, NY: Cambridge University Press.

Moss, P., \& Petrie, P. (2006). From children's services to children's spaces: Public policy, children and childhood. New York, NY: RoutledgeFalmer. 
Osborne, B. J., Carpenter, S., Burnett, M., Rolheiser, C., \& Korpan, C. (Eds.). (2014). Preparing graduate students for a changing world of work [Special issue introduction]. Canadian Journal of Higher Education, 44(3), i-ix.

Quinn Patton, M. (2002). A vision of evaluation that strengthens democracy. Evaluation, 8(1), 125-139.

Rose, M. (2012, September). Graduate student professional development: A survey with recommendations [Report prepared for The Canadian Association for Graduate Studies in conjunction with The Social Sciences and Humanities Research Council of Canada]. Retrieved from http://www.cags.ca/documents/publications/working/ Report\%200n\%20Graduate\%2oStudent\%20Professional\%2oDevelopment\%20\%20 -\%20A\%20survey\%20with\%2orecommendations\%20FINAL\%20Eng.OCT\%202012.pdf

\section{Contact Information}

Cynthia Korpan

LTC Professional Development Programs and TA Training

Learning and Teaching Centre

University of Victoria

tagsa@stlhe.ca

Lianne Fisher works in educational development at the Centre for Pedagogical Innovation at Brock University. She regards working with individuals to (a) facilitate instructional variety, (b) generate better practices to support more learners, more of the time, and (c) facilitate instructional skills workshops as integral to enhancing the teaching and learning of all members of the institution. Lianne co-ordinates and facilitates graduate teaching assistant professional development opportunities at Brock University and is vice-chair of the Teaching Assistant and Graduate Student Advancement Executive.

Lorraine Godden is a $\mathrm{PhD}$ candidate in the policy and cultural studies stream at the Faculty of Education, Queen's University. Lorraine's research interests include career education, the professional development of educators, and the role of mentoring as both support and scaffold for successful professional and leadership development. Lorraine draws on her experience of working in the profit and non-profit sectors, as a teacher and educational manager, and more recently from her qualitative research with at-risk youths, teacher candidates, and education graduate students. Lorraine's doctoral work examines how policy and curriculum implementation processes support educational and professional development.

Shaya Golparian is an educational developer at the Centre for Teaching, Learning, and Technology at the University of British Columbia (UBC). She is involved with various graduate students and TA professional development projects, consults with faculty and department representatives on teaching and learning matters, and facilitates workshops designed to improve teaching and student learning in higher education. Shaya has a PhD in curriculum and pedagogy from UBC. 
Aisha Haque is a language and communication instructor at Western University, where she designs and delivers both online and face-to-face programs to support graduate student development. In particular, her work focuses on helping international teaching assistants improve their teaching and cross-cultural communication skills. Drawing on her background in post-colonial studies, she is currently co-authoring a Western Purple Guide on teaching international students and also teaches courses on Bollywood cinema, at Fanshawe College.

Betsy Keating is the University of Windsor's GATA Network Coordinator. She works with both the Faculty of Graduate Studies and the Centre for Teaching and Learning to develop training, support, resources, and learning community opportunities for graduate students and teaching assistants. Betsy is a doctoral candidate, specializing in cognition and learning in higher education, and a student member-at-large on the Teaching Assistant and Graduate Student Advancement executive. She also enjoys teaching part-time in the Department of English Language, Literature, and Creative Writing.

Cynthia Korpan is the Professional Development Programs and TA training manager in the Learning and Teaching Centre at the University of Victoria. Cynthia plans and develops all professional development for graduate students and co-facilitates Learning and Teaching in Higher Education, a graduate certificate program. Concurrently, she is a PhD interdisciplinary candidate, researching the learning process that TAs undergo as they first begin teaching (as the lead instructor in the classroom) in the academic workplace. Cynthia is Chair (previously Vice-Chair) of the Teaching Assistant and Graduate Student Advancement special interest group within the Society for Teaching and Learning in Higher Education.

Suzanne Le-May Sheffield is the director of the Centre for Learning and Teaching at Dalhousie University, Nova Scotia, managing the centre's daily operations and ongoing program development. She has long had an interest in graduate student development, including co-creating the Certificate in University Learning and Teaching.

Annie Riel is a PhD student in the French Studies program at Queen's University. Her research focuses on the intersections between literature, music, and cinema. She is also a member of the Ellis Hall Active Learning Classrooms Research Group, which studies the impact of space on teaching and learning. Previously, Annie completed a graduate certificate in higher education and a master's degree in creative writing at Université du Québec à Montréal. She is pleased to be a part of the Teaching Assistant and Graduate Student Advancement executive committee, where one of her roles is to facilitate communications between French and English members.

Christina Skorobohacz is a doctoral candidate in educational studies at Brock University, a student member-at-large for the Teaching Assistant and Graduate Student Advancement special interest group of the Society for Teaching and Learning in Higher Education, and a distinguished reviewer for the Journal of Research Practice. She has taught courses in reflection, diversity, writing, and higher education. Her research interests in- 
clude: graduate assistantships, professional development, and identities; academic service, leadership, and followership; and qualitative methods of inquiry. Her publications appear in journals of teaching and learning, and of higher, adult, and general education. She is part of (a) an international writing group investigating followers' experiences of academic leadership in teaching and learning and (b) a research team conducting a scoping study of institutional ethnography.

Roselynn Verwoord is a PhD student in the Department of Educational Studies at the University of British Columbia (UBC). She currently works as a curriculum consultant at the UBC Centre for Teaching, Learning and Technology and is the chair, Student Advocacy on the Board of Directors for the Society for Teaching and Learning in Higher Education.

Kim West is an educational development specialist at the University of Saskatchewan, in graduate student and post-doctoral fellow development at The Gwenna Moss Centre for Teaching Effectiveness. She instructs and leads the development of several graduate courses at her institution that scaffold mentorship opportunities across faculty, staff, postdoctoral fellows, and graduate students. Her research has included co-authoring papers with graduate students on topics such as the nature of trust in higher education, and the process of developing teaching philosophy statements. Kim has a $\mathrm{PhD}$ in earth science and enjoys teaching undergraduate courses from time to time in the Department of Geography and Planning. 